CEPREMAP.

BIBLIOTHEOUE

142, rue du Chevaleret

75013 PARIS

Tél. : 40778420

Is There Always too Little Research in Endogenous Growth with Expanding Product Variety?

\author{
Jean-Pascal BENASSY *†
}

September 1995

Revised June 1996

$N^{\circ} 9615$

Forthcoming, European Economic Review

*I am highly indebted to Peter Howitt for spotting a serious mistake in an earlier version. I also want to thank the referees for their useful comments. Needless to say, I am solely responsible for any remaining deficiencies.

${ }^{\dagger}$ Address : CEPREMAP, 142 rue du Chevaleret, 75013 Paris, France. Telephone : 33-1-40 778462 ; Fax : 33-1-44 243857 ; e-mail : benassy@cepremap.msh-paris.fr 


\title{
Is there always too little research in endogenous growth with expanding product variety?
}

\begin{abstract}
It is generally believed that models of endogenous growth with expanding product variety typically yield a too low level of research. We show here that this result is due to the implicit choice of a particular value for a crucial parameter. Once this parameter is set free, one finds that too much research can occur as well.

JEL Codes : 033

Keywords : Research, Endogenous growth

\section{Fait-on toujours trop peu de recherche dans} les modèles de croissance endogène à la Romer ?

\section{RESUME}

Il existe une opinion extrêmement répandue suivant laquelle les modèles de croissance endogène avec expansion de la variété des produits à la Romer (1990) engendrent toujours un niveau de recherche trop faible. On montre ici que ce résultat est dû au choix implicite d'une valeur particulière pour un paramètre crucial. Quand la valeur de ce paramètre n'est plus contrainte, on trouve que l'on peut aussi bien obtenir un niveau de recherche trop élevé.
\end{abstract}

Codes JEL : 033

Mots clés : Recherche, Croissance endogène 


\section{Introduction}

One of the most popular models of endogenous growth is that based on "expanding product variety" (Romer 1987, 1990), in which technical progress takes the form of the introduction of new varieties of goods. Starting with Romer himself, several authors have emphasized that in this type of models not enough resources were typically devoted to research as compared to the social optimum, and that as a result growth was inefficiently low. This too low level of research was actually found in a variety of different specifications (see for example Romer, 1990, Grossman and Helpman, 1991b, Barro and Sala-i-Martin, 1995), and as a consequence this feature was soon perceived by many people as an intrinsic aspect of this class of models, and underlined as differentiating them from the alternative "Schumpeterian" models of vertical innovation (Aghion and Howitt, 1992, Grossman and Helpman, 1991a,b), which can typically lead to too high or too low levels of innovation and growth.

We want to show here that this apparent asymmetry between the two lines of models is due to the implicit setting of a crucial parameter in "Romerian" models, namely the "returns to specialization", at an arbitrary specific value. Once this parameter is allowed to take more general values, Romer's model can lead to too high rates of research and growth as well as to the too low rates usually found.

\section{A traditional model}

Since Romer's initial contributions, several adaptations of his model have been made. We shall use for our demonstration a model due to Grossman and Helpman (1991b), which has at least two advantages : (a) They propose in the same book a "Schumpeterian" model, which the interested reader can compare directly to the one developed here ; (b) there is only one accumulated factor, "patents", so that we shall not have to bother with any transitional dynamics. 


\section{Households}

Households are infinitely lived and endowed with a constant aggregate flow of labor $L$. They consume $C(t)$ and maximize discounted utility :

$$
\int_{0}^{\infty} e^{-\rho t} U[C(t)] d t
$$

Following Grossman and Helpman (1991b), we shall in the main body of this article take $U[C(t)]=\log [C(t)]$. More general isoelastic functions are studied in a longer version available from the author.

\section{Production}

There are three sectors of production. The consumption goods sector produces output $Y$ with the help of intermediate goods indexed by $\mathrm{j}^{1}$ :

$$
Y=\left[\int_{0}^{n} x(j)^{\alpha} d j\right]^{1 / \alpha} \quad 0<\alpha<1
$$

where $x(j)$ is the amount of intermediate $j$ and $[0, n(t)]$ is the range of intermediate goods existing at time $t$.

The number of intermediate goods can be increased by undertaking research, which uses labor. The "production function" in the research sector shows how much $n(t)$ expands as a function of the quantity of labor $\ell(t)$ devoted to research :

$$
\frac{\dot{n}}{n}=\frac{\ell}{a}
$$

Finally each intermediate good $j \in[0, n(t)]$ is produced by a monopolistically competitive firm $j$ with production function :

$$
x_{j}=\ell_{j}
$$

\footnotetext{
${ }^{1}$ Note that Grossman and Helpman (1991b) actually assume that households consume directly the intermediates, replacing somehow $C$ by $Y$ in the utility function. We keep here the more traditional "production" approach (Ethier, 1982) and will return to this point in section 7 below.
} 


\section{Disentangling market power and returns to specialization}

As it turns out, parameter $\alpha$ in the production function (2) is a most important one, which actually serves simultaneously two purposes since the quantity $1 / \alpha-1$ is both an index of market power and the degree of returns to specialization. Let us see those in turn.

Because (2) is C.E.S. in its arguments, the demand for each intermediate $j$ is isoelastic with elasticity $-1 /(1-\alpha)$. As a result each monopolistically competitive firm $j$ will have a markup of price over cost equal to $1 / \alpha-1$.

But $1 / \alpha-1$ is also the degree of returns to specialization (Ethier, 1982). Assume indeed that a quantity of labor $X$ is devoted to the production of intermediates, and spread evenly between the $n$ brands. Then $x_{j}=X / n$ and from function (2) :

$$
Y=\dot{n}^{1 / \alpha-1} X
$$

so that $1 / \alpha-1$ adequately measures the degree to which society benefits from "specializing" production between a larger number of intermediates $n$, and is called the "degree of returns to specialization".

Of course one immediately notices that there is a one to one relationship between the monopolistic markup and the degree of returns to specialization (they are actually equal here). But this relation is purely due to the particular C.E.S. function used in (2). While practically all authors in the area have used it, it is by no means generic, and the original formulation of such production functions by Ethier (1982) clearly separated the returns to specialization and the monopolistic markup. This we shall also do by using from now on the following production function for final goods :

$$
Y=n^{\nu+1-1 / \alpha}\left[\int_{0}^{n} x(j)^{\alpha} d j\right]^{1 / \alpha}
$$

The monopolistically competitive markup is still equal to $1 / \alpha-1$. As for the degree of returns to specialization, let us take again $x_{j}=X / n$, which yields:

$$
Y=n^{\nu} X
$$


so that the degree of returns to specialization is now equal to $\nu$, which can thus be set independently of $\alpha$. At this stage we shall only make the natural assumption $\nu \geq 0$.

We are now ready to study in turn the market solution and social optimum, and see that their comparison will be substantially modified by the generalization to production function (5).

\section{The market solution}

Since both the market solution and the social optimum will be symmetric in the various intermediates $j$, we shall from the start give the equilibrium relations without mentioning the corresponding indexes.

Since the final goods sector is competitive, the price $p$ of intermediates in terms of the final good (chosen as a numéraire) is simply equal to their marginal productivity, which yields:

$$
p=n^{\nu}
$$

Since the research sector is also competitive, the wage $w$ and the value $v$ of the patent for an additional "brand" $j$ are related by:

$$
v=\frac{a w}{n} \quad \text { if } \quad \dot{n}>0
$$

Now the marginal cost of producing each intermediate is equal to $w$ in view of (4). Therefore with a monopolistic markup of $1 / \alpha-1$ in the intermediate industry:

$$
p=\frac{w}{\alpha}
$$

As a consequence, calling $x=X / n$ the employment in intermediate industry $j$, the flow of profits $\pi$ accruing to the holder of a patent is :

$$
\pi=(p-w) x=\frac{(1-\alpha) p X}{n}
$$

Now we have to derive the optimal choices of the households, which can choose between consuming now or accumulating new patents via a positive $\dot{n}$. Their optimization program is written : 


$$
\begin{gathered}
\operatorname{Max} \int_{0}^{\infty} e^{-\rho t} \log C d t \quad \text { s.t. } \\
C+v \dot{n}=w L+\pi n
\end{gathered}
$$

The hamiltonian for this program is :

$$
H=\log C+\lambda\left(\frac{w L+\pi n-C}{v}\right)
$$

and the first order conditions :

$$
\begin{gathered}
\frac{1}{C}=\frac{\lambda}{v} \\
\dot{\lambda}=\rho \lambda-\frac{\lambda \pi}{v}
\end{gathered}
$$

Eliminating $\lambda$ between them we find:

$$
\frac{\dot{C}}{C}=\frac{\pi}{v}+\frac{\dot{v}}{v}-\rho
$$

a condition analogue to the more traditional $\dot{C} / C=r-\rho$ if one remembers that the return on patents must now include the capital gains $\dot{v} / v$.

In order to complete the solution, we still have conditions of equilibrium on goods and labor markets. The first is that consumption be equal to final goods output, which, assuming that a quantity of labor $X$ is used in the production of intermediates, is written:

$$
C=n^{\nu} X
$$

Secondly the quantity of labor used in research must be equal to $L-X$, which, plugged into equation (3), yields :

$$
\frac{\dot{n}}{n}=\frac{L-X}{a}
$$

Equations (7) to (13) fully define the dynamics of the economy. Now using $(7),(8),(9)$ and $(10)$, one obtains: 


$$
\begin{aligned}
& \frac{\dot{v}}{v}=(\nu-1) \frac{\dot{n}}{n} \\
& \frac{\pi}{v}=\frac{1-\alpha}{\alpha} \frac{X}{a}
\end{aligned}
$$

Combining equations (11) to (15), we finally find the following dynamic equation for $X$ :

$$
\frac{\dot{X}}{X}=\frac{X}{\alpha a}-\frac{L}{a}-\rho
$$

One immediately jumps to a steady state characterized by a constant $X$, and therefore a constant growth rate of patents $g=\dot{n} / n$ which, taking into account the fact that $n$ cannot decrease, is computed from equations (13) and (16) as:

$$
g=\max \left[0, \frac{(1-\alpha) L}{a}-\alpha \rho\right]
$$

We may note here that, according to the standard intuition in this line of models, the rate of growth of patents is an increasing function of the monopolistic markup $1 / \alpha-1$.

\section{The social optimum}

Computation of the social optimum will actually be easier than that of the market solution. Indeed all the planner has to do is to choose which quantity of labor $X$ will be devoted to the production of intermediate goods, the rest, $L-X$, being devoted to research. Since $C=n^{\nu} X$, the program of the social planner is thus :

$$
\begin{gathered}
\operatorname{Max} \int_{0}^{\infty} e^{-\rho t} \log \left(n^{\nu} X\right) d t \quad \text { s.t. } \\
\frac{\dot{n}}{n}=\frac{L-X}{a}
\end{gathered}
$$


In order to have a simpler solution, let us make the change of variables $N=\log n$. The above program is now rewritten:

$$
\begin{gathered}
\operatorname{Max} \int_{0}^{\infty} e^{-\rho t}(\log X+\nu N) d t \quad \text { s.t. } \\
\dot{N}=\frac{L-X}{a}
\end{gathered}
$$

The hamiltonian for this program is:

$$
H=\log X+\nu N+\frac{\lambda(L-X)}{a}
$$

We may note that this hamiltonian is concave in the variables $X$ and $N$ so that the first order conditions will indeed yield a maximum. These first order conditions are:

$$
\begin{gathered}
\frac{1}{X}=\frac{\lambda}{a} \\
\dot{\lambda}=\rho \lambda-\nu
\end{gathered}
$$

which combined together yield:

$$
\frac{\dot{X}}{X}=\frac{\nu X}{a}-\rho
$$

The economy immediately settles to a steady state characterized by a constant $X$, and an optimal rate of growth $\dot{n} / n=g^{*}$ given by :

$$
g^{*}=\max \left[0, \frac{L}{a}-\frac{\rho}{\nu}\right]
$$

Here we see that the optimal rate of growth does not depend at all on $\alpha$, but only on the returns to variety $\nu$. This is quite natural as, from equation (6), the social rate of return on research critically depends on $\nu$. 


\section{Comparing market outcome and social op- timum}

Looking first at formulas (17) and (19) giving the market and optimal rates of growth for $n$, respectively $g$ and $g^{*}$, we see that if $\alpha$ and $\nu$ are given independently, we cannot make any definite comparison between $g$ and $g^{*}$ : The amount of labor devoted to research, and accordingly the growth rate, can be too high or too low.

The intuition for this result is actually quite clear: because the returns to specialization $\nu$ can be chosen independenly of $\alpha$, the social rate of return on research, and accordingly the optimal rate of growth of patents, can be made as small as wanted, and even zero for $\nu<a \rho / L$. It is therefore trivial to find, by simple comparison of (17) and (19), combinations of $\alpha$ and $\nu$ such that the market rate of growth is excessive.

But formulas (17) and (19) also give us the key to the result usually found in the literature, i.e. that the amount of research is too low. Indeed we saw in section 3 that the use of the "traditional" production function (2) was equivalent to taking $\nu=1 / \alpha-1$. Plugging this value into formula (19) we obtain:

$$
g^{*}=\frac{1}{1-\alpha} \max \left[0, \frac{(1-\alpha) L}{a}-\alpha \rho\right]
$$

so that $g^{*}$, as given by (20), is now always above the market solution given by (17). This "traditional" result was thus only due to the choice of a particular value for the returns to specialization!

\section{Taste for variety}

All the analysis was carried here assuming, as in Ethier (1982) that the returns to specialization were occurring within the production sphere via function (5). An alternative way to proceed (actually the one used in Grossman and Helpman, 1991b) is to assume that households directly consume the intermediate goods and that they display some "taste for variety". This is simply done by writing their utility function, as in (1):

$$
\int_{0}^{\infty} e^{-\rho t} U[C(t)] d t
$$



by:

$C$ must now be interpreted as an "aggregate consumption index", defined

$$
C=n^{\nu+1-1 / \alpha}\left[\int_{0}^{n} x(j)^{\alpha} d j\right]^{1 / \alpha}
$$

where $x(j)$ is the consumption of good $j$ by the household. We should note here that the index $C$ in equation (21) displays a "taste for variety" which, unlike in the traditional literature, is disentangled from the parameter $\alpha$ determining monopolistic power (see Benassy, 1996, for an analysis of some consequences). The analysis would proceed in that case in a way parallel to that studied in the text and yield similar results.

\section{Conclusions}

It has been found in many different models of endogenous growth with expanding product variety that market forces lead to too little research and growth as compared to the social optimum. Although that result might have seemed a general one, at least for the simple C.E.S. functions commonly used in these models, we saw in this article that this was actually due to the implicit choice of a particular value for the parameter giving the "returns to specialization" or "taste for variety", and that if one could choose different values, then no a priori ranking existed between the market and optimal rates of growth. This generalization was made while keeping the simple and tractable C.E.S. structure.

Although the analysis was carried out in a specific model, the reader can check that the analysis applies as well to other such models. This teaches us two conclusions: First, one important asymmetry between horizontal and vertical innovation models of endogenous growth was only due to the arbitrary choice of a strategic parameter in "horizontal innovation" models ${ }^{2}$. Secondly most normative pronouncements, concerning notably corrective policies, based on the one sided comparison between market and socially optimal

\footnotetext{
${ }^{2}$ Another way to make this asymmetry disappear is of course to mix the two lines of work. For example Stokey (1995) introduces elements of "variety" in a model of vertical innovation. She finds possibilities of overinvestment as well, but the mechanisms leading to it (business stealing, congestion externalities in research) are actually more akin to those emphasized in the vertical innovation literature, and quite different from the one presented here.
} 
rates of innovation in such models must be revised in light of the fact that there is not anymore any clearcut ranking between the two.

\section{References}

[1] AGHION, Philippe, and HOWITT, Peter (1992), "A Model of Growth through Creative Destruction", Econometrica, vol. 60, pp 323-351.

[2] BARRO, Robert and SALA-I-MARTIN, Xavier (1995), Economic Growth, Mac Graw-Hill, New York.

[3] BENASSY, Jean-Pascal (1996), "Taste for Variety and Optimum Production Patterns in Monopolistic Competition", Economics Letters, vol. 51, pp xxx-xxx.

[4] ETHIER, Wilfred J. (1982), "National and International Returns to Scale in the Modern Theory of International Trade", American Economic Review, vol. 72 , pp 389-405.

[5] GROSSMAN, Gene M. and HELPMAN, Elhanan (1991a), "Quality Ladders in the Theory of Growth", Review of Economic Studies, vol. 58, pp 43-61.

[6] GROSSMAN, Gene M. and HELPMAN, Elhanan (1991b), Innovation and Growth in the Global Economy, The M.I.T. Press, Cambridge, Massachusetts.

[7] ROMER, Paul M. (1987), "Growth Based on Increasing Returns Due to Specialization", American Economic Review, vol. 77, Papers and Proceedings, pp 56-62.

[8] ROMER, Paul M. (1990), "Endogenous Technical Change", Journal of Political Economy, vol. 98, supplement, pp 71-102.

[9] STOKEY, Nancy L. (1995), "R and D and Economic Growth" Review of Economic Studies, vol. 62, pp 469-489. 